\title{
Effect of Sports Vision Training on Vision Skills and Batting Performance of Male Cricket Players
}

\author{
Dr. Pawan Kumar ${ }^{1 *}$, Dr. (Mrs.) Vasanthi Kadhiravan ${ }^{2}$ \\ ${ }^{1}$ PTI, Government Senior Secondary School, Baijalpur, Old Fatehabad, Fatehabad, Haryana 125050, India \\ ${ }^{2}$ Professor, Department of Physical Education, University of Mumbai, Mahatma Gandhi Road, Kolivery Village, University of Mumbai, Vidya Nagari, \\ Kala Ghoda, Fort, Mumbai, Maharashtra 400032, India
}

DOI: $10.36348 /$ jaspe.2021.v04i01.001 | Received: 22.12.2020 | Accepted: 03.01.2021 | Published: 08.01 .2021

*Corresponding author: Dr. Pawan Kumar

\section{Abstract}

The purpose of this study was to see the effect of sports vision training on vision skills and batting performance of male cricket players. To achieve the purpose of the study 30 male cricket players from 100 club level male cricket players age ranging between 16 to 25 years, were randomly selected as subjects. The selected 30 male cricketers were undergone the sports vision training for 12 weeks, three days in a week in the morning session for 30 minutes duration. The Pre- test and the Post-test were conducted on the selected vision skills and batting performance variables of the subjects. The criterion measures chosen to test the hypotheses were Paired " $t$ " test. The hypotheses were tested at 0.05 levels of significance. The result revealed that sports vision training showed significant improvement on vision skills and batting performance of male cricket players. Sports vision training is therefore an efficient method of improving certain vision skills and batting performance of male cricket players.

Keywords: Sports vision training, Vision skills, Cricket.

Copyright (c) 2021 The Author(s): This is an open-access article distributed under the terms of the Creative Commons Attribution 4.0 International License (CC BY-NC 4.0) which permits unrestricted use, distribution, and reproduction in any medium for non-commercial use provided the original author and source are credited.

\section{INTRODUCTION}

Cricket is basically a bat and ball game played between two teams of eleven players. It is one of the oldest sports in the world. The game of Cricket has historically been known as 'the gentleman's game'. To participate in a competitive sport, such as cricket, one of the main aspects any coach should keep in mind is that it is vital to achieve the best possible performance from the whole body - including the vision system. In cricket it is possible that success is achieved by accurately made decisions, based on the information obtained by visual input. Cricket requires an incredible amount of vision skills especially for batsman. Vision skills are the key to a cricket player's timing, coordination and overall performance. The vision system is like any other motor system in the body. It can be trained and improved through specific exercises just as athletes use sport-specific drills to improve overall sporting performance. There are many evidences which support the claims of vision sports training playing an important role in enhancing sports performance. Many studies have been conducted on the effect of sport vision training on vision skills of athletes in various sporting domains such as table tennis [1], rugby [2, 3], tennis [4, 5], netball [6] and field hockey [7]. Studies have also examined the effect of vision skill training on the visual skills of cricketers. Research from these studies provides evidence that visual training programmes can lead to an improvement in the visual skills of cricket players [8-10]. The conclusion from these studies is that the basic vision skills can be improved through sports vision training. Therefore, it is assumed that sports vision trainings help the cricket batsman to resolve their problems related to bating performance.

\section{OBJECTIVES OF THE STUDY}

- To see the effect of sports vision training on eye hand coordination of male cricket players.

- To see the effect of sports vision training on eye foot coordination of male cricket players.

- To see the effect of sports vision training on visual reaction time of male cricket players

- To see the effect of sports vision training on depth perception of male cricket players

- To see the effect of sports vision training on visual acuity (dynamic) of male cricket players

- To see the effect of sports vision training on batting performance of male cricket players. 


\section{HYPOTHESES STATEMENT}

$\mathrm{H}_{1}$ : Sports vision training program will show significant improvement in eye-hand coordination of male cricket players.

$\mathrm{H}_{2}$ : Sports vision training program will show significant improvement in eye-foot coordination of male cricket players.

$\mathrm{H}_{3}$ : Sports vision training program will show significant improvement in visual reaction time of male cricket players.

$\mathrm{H}_{4}$ : Sports vision training program will show significant improvement in depth perception of male cricket players.

$\mathrm{H}_{5}$ : Sports vision training program will show significant improvement in visual acuity (dynamic) of male cricket players.

$\mathrm{H}_{6}$ : Sports vision training program will show significant improvement in batting performance of male cricket players.

\section{SIGNIFICANCES OF THE STUDY}

- The proposed study will help cricket players and coaches so that they can use this training program which included sports vision training in their training.

- This study will give the scientific basis of training to improve the visual skills of cricket players.

- This study may give an opportunity and encouragement to the interested research scholars to conduct further studies on sports vision training on the other games.

\section{DELIMITATIONS OF THE STUDY}

- This study was delimited only to cricket players in the age group of 16 to 25 years.
- The study was delimited to 30 subjects of male cricket players.

- This study was delimited to club level male cricket players from Mumbai, having an experience of at least one year of playing competitive cricket.

- Training was delimited to 12 weeks, three days in a week in the morning session for 30 minutes duration.

- This study was to delimited to sports vision skills and batting performance of male cricket players.

\section{RESEARCH DESIGN}

This single group experimental study was designed to see the effect of sports vision training on vision skills and batting performance of male cricket players. To achieve the purpose of the study 30 male cricket players from 100 club level male cricket players from Mumbai, were randomly selected as subjects. The selected 30 male cricketers were undergone the sports vision training for 12 weeks, three days in a week in the morning session for 30 minutes duration. The Pre- test and the Post-test were conducted on the selected vision skills and batting performance variables of the subjects.

\section{STATISTICAL ANALYSIS}

The hypotheses of the study were tested using Paired "t" test was used to analyse the effect of sports vision training on vision skills and batting performance of male cricket players. The hypotheses were tested at 0.05 levels of significance. The descriptive statistics such as means, standard deviation also calculated to generate the nature of data.

\section{RESULT AND FINDINGS}

Table-1: Analysis of pre and post test data of vision skills and batting performance of experimental group

\begin{tabular}{|c|c|c|c|c|c|c|c|c|}
\hline S. No & $\begin{array}{l}\text { Criterion } \\
\text { variables }\end{array}$ & Group & Mean & SD & SEM & $\mathbf{T}$ & Df & $\begin{array}{l}\text { Standard Error of } \\
\text { Difference }\end{array}$ \\
\hline 1. & Eye hand coordination & $\begin{array}{l}\text { Pre test } \\
\text { Post test }\end{array}$ & $\begin{array}{l}30.40 \\
33.03\end{array}$ & $\begin{array}{l}4.45 \\
4.51 \\
\end{array}$ & $\begin{array}{l}0.81 \\
0.82\end{array}$ & 15.545 & 29 & 0.169 \\
\hline 2 & Eye foot coordination & $\begin{array}{l}\text { Pre test } \\
\text { Post test }\end{array}$ & $\begin{array}{l}5.229 \\
3.919 \\
\end{array}$ & $\begin{array}{l}0.6435 \\
0.5362 \\
\end{array}$ & $\begin{array}{l}0.1175 \\
0.0979\end{array}$ & 20.1187 & 29 & 0.065 \\
\hline 3 & Visual reaction time & $\begin{array}{l}\text { Pre test } \\
\text { Post test }\end{array}$ & $\begin{array}{l}13.90 \\
10.20\end{array}$ & $\begin{array}{l}1.37 \\
1.45\end{array}$ & $\begin{array}{l}0.25 \\
0.26\end{array}$ & 22.1390 & 29 & 0.167 \\
\hline 4 & Depth perception & $\begin{array}{l}\text { Pre test } \\
\text { Post test }\end{array}$ & $\begin{array}{l}5.120 \\
3.363\end{array}$ & $\begin{array}{l}1.488 \\
1.488\end{array}$ & $\begin{array}{l}0.272 \\
0.229\end{array}$ & 15.6129 & 29 & 0.113 \\
\hline 5 & $\begin{array}{l}\text { Visual acuity } \\
\text { (dynamic) }\end{array}$ & $\begin{array}{l}\text { Pre test } \\
\text { Post test }\end{array}$ & $\begin{array}{l}0.627 \\
0.763 \\
\end{array}$ & $\begin{array}{l}0.120 \\
0.150\end{array}$ & $\begin{array}{l}0.022 \\
0.027\end{array}$ & 8.4115 & 29 & 0.016 \\
\hline 6 & Batting performance & $\begin{array}{l}\text { Pre test } \\
\text { Post test }\end{array}$ & $\begin{array}{l}17.313 \\
23.527\end{array}$ & $\begin{array}{l}7.097 \\
8.662\end{array}$ & $\begin{array}{l}1.296 \\
1.581\end{array}$ & 8.6370 & 29 & 0.719 \\
\hline
\end{tabular}




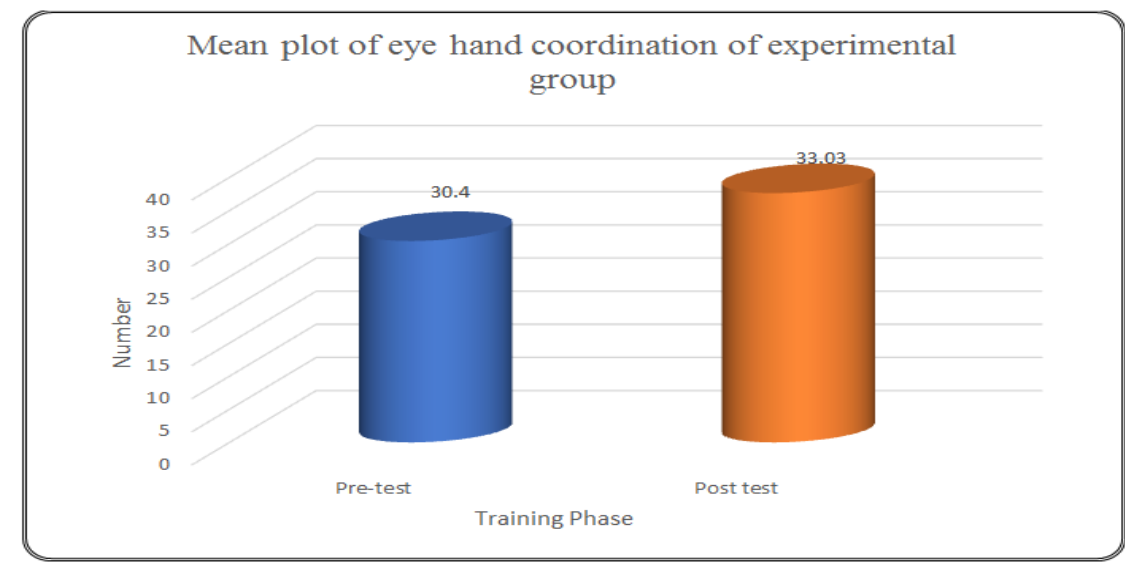

Graph-1: Mean plot of eye hand coordination of experimental group

From the above Graph-1 it is evident that after 12 weeks of sports vision training the mean difference in eye hand coordination of the experimental group was significant. Thus, the 12 weeks duration of the sports vision training program was effective for the improvement of eye hand coordination of male cricket players. Hence hypothesis $\mathrm{H}_{1}$ : "Sports Vision Training will show significant improvement in eye hand coordination of male cricket players", is accepted.

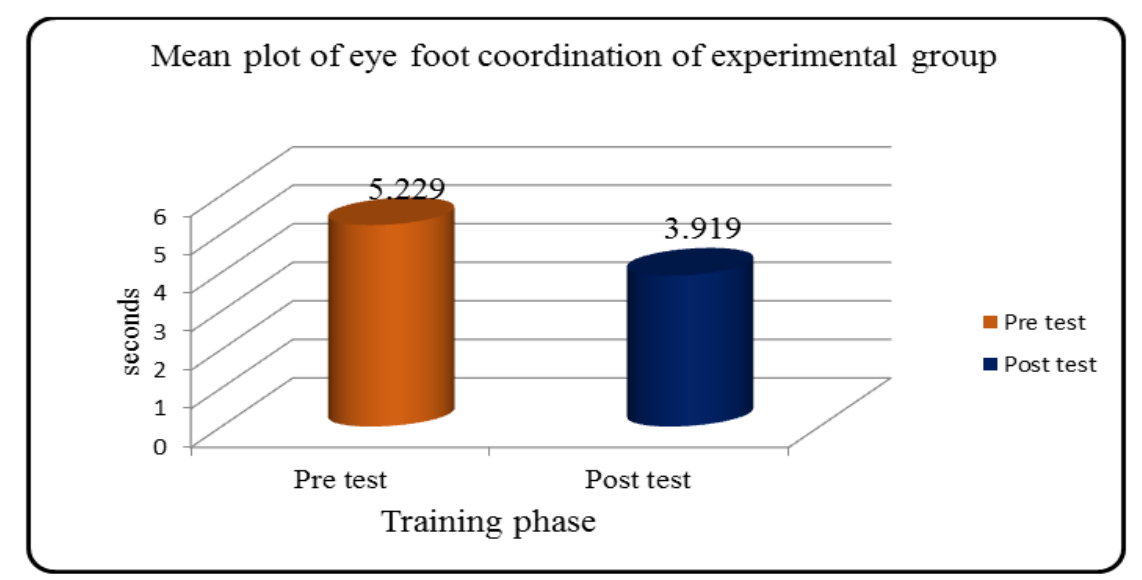

Graph-2: Mean plot of eye foot coordination of experimental group

From the above Graph-2 it is evident that after 12 weeks of sports vision training the mean difference in eye foot coordination of the experimental group was significant. Thus, the 12 weeks duration of the sports vision training program was effective for the improvement of eye foot coordination of male cricket players. Hence hypothesis $\mathrm{H}_{2}$ : "Sports Vision Training will show significant improvement in eye foot coordination of male cricket players", is accepted.

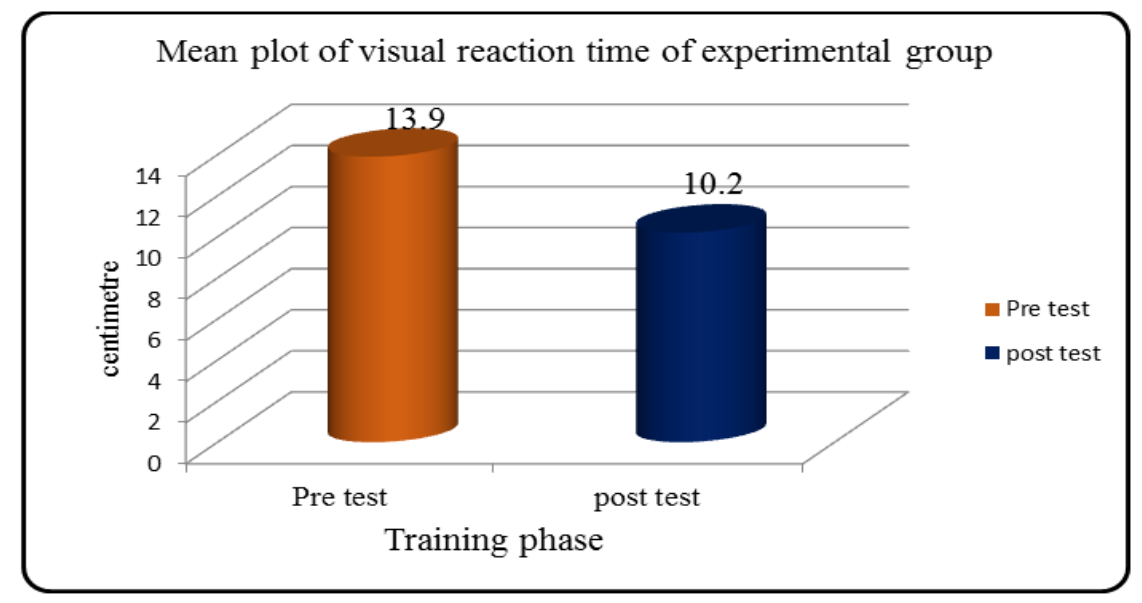

Graph-3: Mean plot for visual reaction time of experimental group 
From the above Graph-3 it is evident that after 12 weeks of sports vision training the mean difference in visual reaction time of the experimental group was significant. Thus, the 12 weeks duration of the sports vision training program was effective for the improvement of visual reaction time of male cricket players. Hence hypothesis $\mathrm{H}_{3}$ : "Sports Vision Training will show significant improvement in visual reaction time of male cricket players", is accepted.

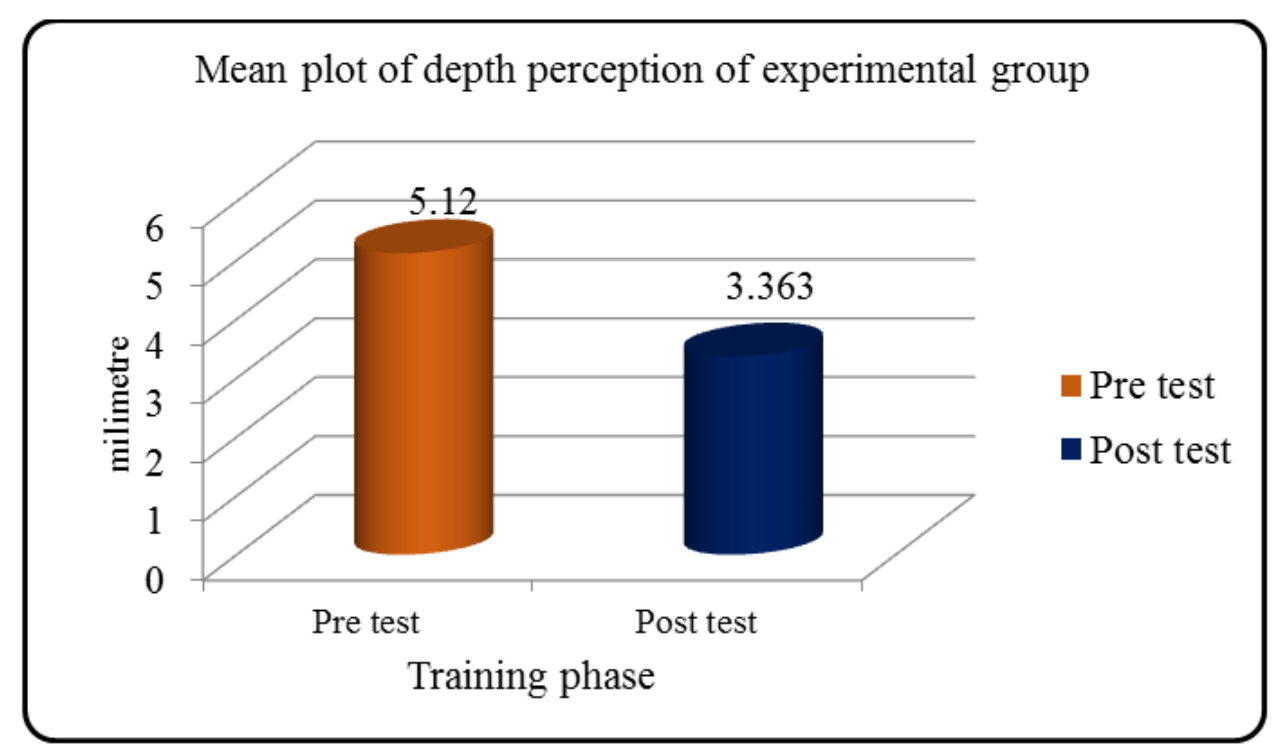

Graph-4: Mean plot for depth perception of experimental group

From the above Graph- 4 it is evident that after 12 weeks of sports vision training the mean difference in depth perception of the experimental group was significant. Thus, the 12 weeks duration of the sports vision training program was effective for the improvement of depth perception of male cricket players. Hence hypothesis $\mathrm{H}_{4}$ : "Sports Vision Training will show significant improvement in depth perception of male cricket players", is accepted.

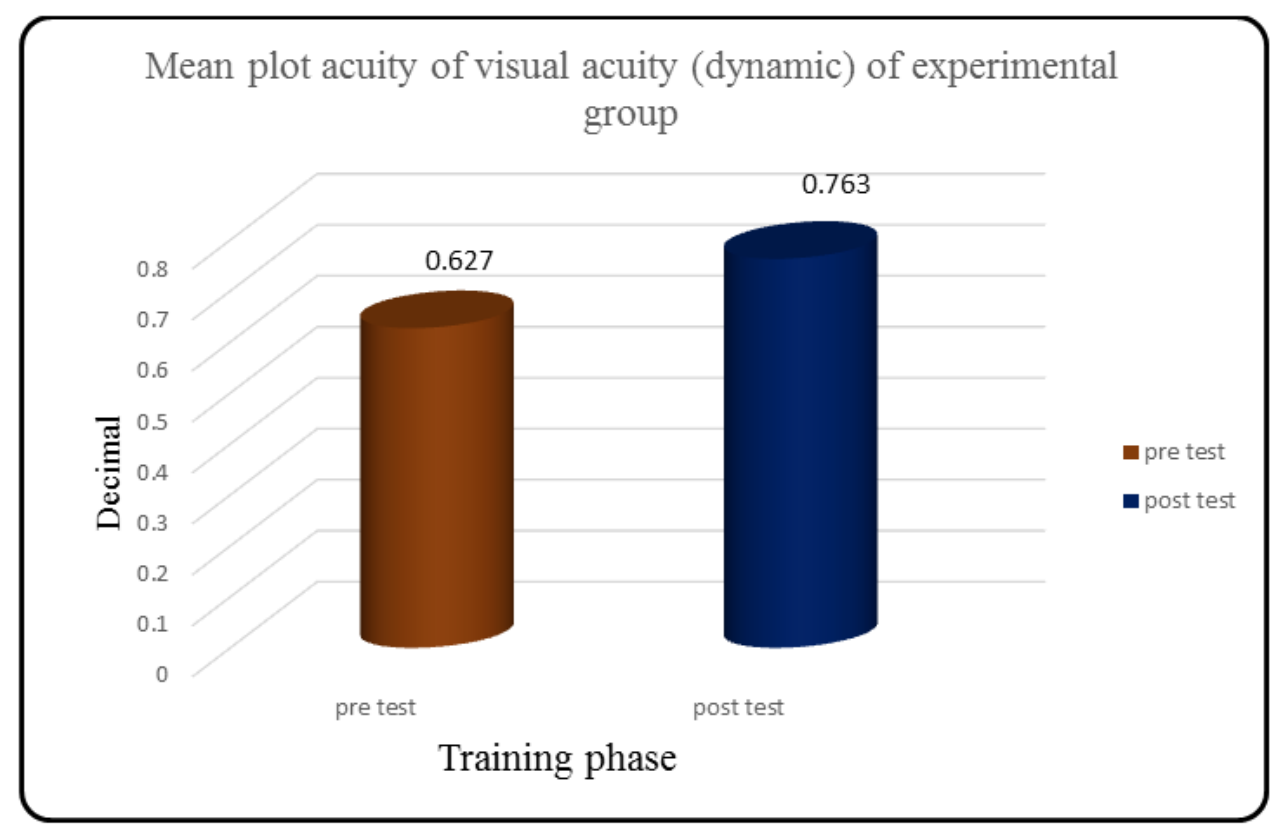

Graph-5: Mean plot for visual acuity (dynamic) of experimental group

From the above Graph-5 it is evident that after 12 weeks of sports vision training the mean difference in visual acuity (dynamic) of the experimental group was significant. Thus, the 12 weeks duration of the sports vision training program was effective for the improvement of visual acuity of male cricket players. Hence hypothesis $\mathrm{H}_{5}$ : "Sports Vision Training will show significant improvement in visual acuity (dynamic) of male cricket players", is accepted. 


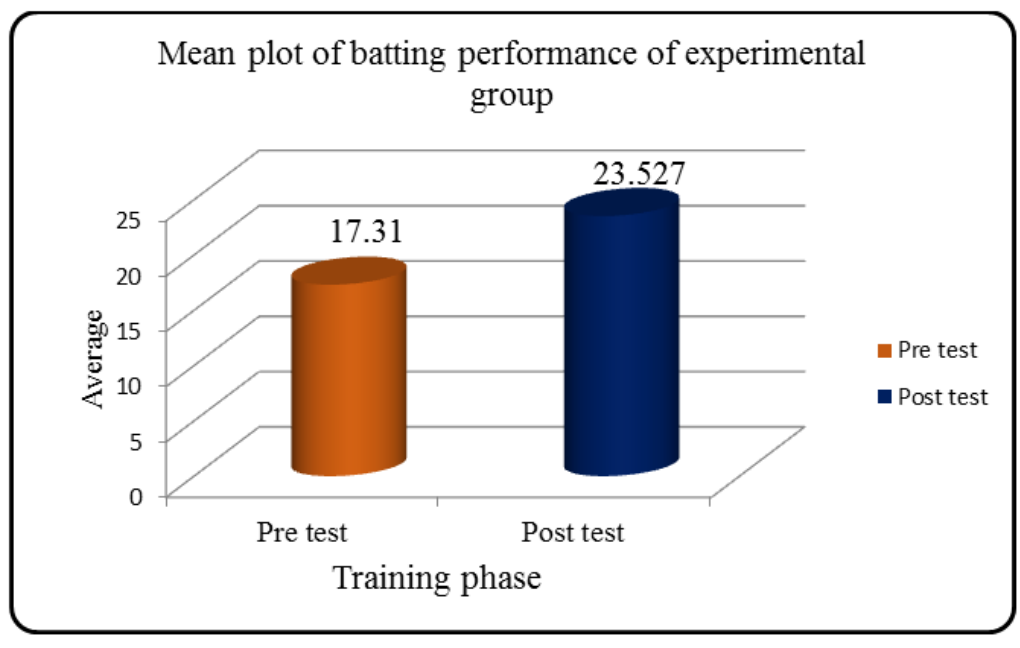

Graph-6: Mean Plot for batting performance of experimental group

From the above Graph-6 it is evident that after 12 weeks of sports vision training the mean difference in batting performance of the experimental group was significant. Thus, the 12 weeks duration of the sports vision training program was effective for the improvement of batting performance of male cricket players. Hence hypothesis $\mathrm{H}_{6}$ : "Sports Vision Training will show significant improvement in batting performance of male cricket players", is accepted.

\section{CONCLUSIONS}

From the analysis of the data, the following conclusion are drawn given below.

- Sports vision training program had showed significant improvement in eye hand coordination of male cricket players.

- Sports vision training program had showed significant improvement in eye foot coordination of male cricket players.

- Sports vision training program had showed significant improvement in visual reaction time of male cricket players.

- Sports vision training program had showed significant improvement in depth perception of male cricket players.

- Sports vision training program had showed significant improvement in visual acuity (dynamic) of male cricket players.

- Sports vision training program had showed significant improvement in batting performance of male cricket players.

\section{REFERENCES}

1. Elder, Russel, Sluyter, Collins., "Dynamic visual acuity training in cricket players", optometry \& visual performance, (2015),3(2),Pp159-168.

2. Du Toit, P. J., Kruger, P. E., Joubert, A., \& Lunsky, J. (2007). Effects of exercise on the visual performance of female rugby players:: sport science. African Journal for Physical Health Education, Recreation and Dance, 13(3), 267-273.

3. Du Toit, P. J., Kruger, P. E., Fowler, K. F., Govender, C., \& Clark, J. (2010). Influence of sports vision techniques on adult male rugby players: sports vision. African Journal for Physical Health Education, Recreation and Dance, 16(3), 487-494.

4. Maman, P., Gaurang, S., \& Sandhu, J. S. (2011). The Effect of Vision Training On Performance In Tennis Players. Serbian Journal of Sports Sciences, 5(1).

5. Tsetseli, M., Malliou, V., Zetou, E., Michalopoulou, M., \& Kambas, A. (2010). The effect of coordination training program on the development of tennis service technique. Biology of Exercise, 6(1).

6. Bressan, W. (2003). Biological control of maize seed pathogenic fungi by use of actinomycetes. Biocontrol, 48(2), 233-240.

7. Schwab, S., \& Memmert, D. (2012). The impact of a sports vision training program in youth field hockey players. Journal of sports science \& medicine, 11(4), 624-631.

8. Kruger, C. S. (2009). The role of visual skills and its impact on skill performance of cricket players. African Journal for Physical Health Education Recreation, 15(4):605-623.

9. Tate, B., Paul, M., \& Jaspal, S. (2008). The impact of visual skills training program on batting performance in cricketers. Serbian Journal of Sports Sciences, 2(1), 17-23.

10. Calder, S. L., \& Kluka, D. A. (2009). The efficacy of the EyeThinkSport training software programme on South African high school cricketers:: sport psychology. African Journal for Physical Health Education, Recreation and Dance, 15(1), 44-61. 